\title{
O RIO LONGÁ E O POVOAMENTO DO NORTE DO PIAUÍ
}

José Luis Lopes Araújo ${ }^{1}$

jlopesaraujo@oi.com.br

Accyolli Rodrigues Pinto de Sousa*

RESUMO: A bacia do rio Longá representou importante fator de povoamento do norte do Piauí, em face dos recursos ambientais que apresenta, tanto em relação à disponibilidade de águas subterrâneas e superficiais, como na biodiversidade caracterizada por rica flora e fauna onde se destacam espécies vegetais que facilitaram a instalação dos primeiros habitantes, ao fornecerem frutos para alimentação humana e animal, e ainda madeira e palha para a construção de habitações e confecção de bens utilitários, a exemplo do tucum, babaçu e carnaúba. Ressalte-se que a cera de carnaúba ainda continua a ser um dos principais produtos da pauta de exportação do Piauí nesta primeira década do século XXI. Além das tradicionais atividades econômicas presentes na bacia do Longá desde os primórdios da colonização, neste início de século já se observa a utilização de técnicas modernas de produção como o uso da irrigação, o que reforça a importância dos recursos hídricos ali presentes, especialmente o rio principal, que é o Longá. Assim esse estudo desenvolveu-se com o objetivo caracterizar os aspectos naturais, conhecer o processo de povoamento, identificar as atividades econômicas mais expressivas desenvolvidas na área dessa bacia, e caracterizar a atividade turística mais preponderante. A metodologia na consulta a material bibliográfico referente ao tema, como livros, artigos, monografias, e consultas na internet e observação in loco. Pode-se concluir que a bacia requer atenção dos gestores públicos e das comunidades que a habitam, pois ações preventivas precisam ser tomadas no sentido de conservar esse rico patrimônio do Piauí.

\footnotetext{
1 Doutor em Geografia Humana pela Universidade de São Paulo. Professor do Departamento de Geografia e História e do Programa de Pós Graduação em Desenvolvimento e Meio Ambiente da Universidade Federal do Piauí.

** Mestrando em Desenvolvimento e Meio Ambiente pela Universidade Federal do Piauí. Bolsista CNPq/ PRODEMA.
} 
PALAVRAS CHAVE: Processo de Povoamento, Pecuária, Extrativismo Vegetal, Turismo.

INTRODUÇÃO

A bacia hidrográfica do rio Longá situa-se na porção norte do estado do Piauí. Esse rio constitui-se um dos principais afluentes do rio Parnaíba pelo lado do Piauí. A drenagem do rio Longá é composta por rios e riachos de caráter intermitente, entre os quais se destacam: Matos, Piracuruca, Surubim e Jenipapo. Convém salientar que no rio Longá situa-se a Cachoeira do Urubu, localizada entre os municípios de Esperantina e Batalha. As atividades econômicas que se destacam na área dessa bacia são: pecuária, agricultura e extrativismo vegetal. Na agropecuária destacam-se projetos de irrigação em alguns municípios dessa bacia como: Buriti dos Lopes, Barras e Campo Maior.

O presente trabalho tem como objetivo geral analisar os diversos usos da bacia do rio Longá pelas comunidades dos municípios que acompõem. Objetivos específicos: 1) caracterizar os aspectos naturais da bacia do rio Longá; 2) conhecer o processo de povoamento dos principais municípios dessa bacia; 3) identificar as atividades econômicas mais expressivas que são desenvolvidas na área dessa bacia, e 4) caracterizar a atividade turística mais preponderante.

A metodologia caracteriza-se basicamente com uso de material bibliográfico referente ao tema como livros, artigos, monografias e consultas na internet. Sendo que ainda foram utilizados dois programas de geoprocessamento para a elaboração dos mapas como: carta linx e o arc view

\section{A BACIA HIDROGRÁFICA DO RIO LONGÁ: CARACTERÍSTICAS}

A bacia do rio Longá está localizada na área da bacia hidrográfica do rio Parnaíba formando uma das grandes sub-bacias do Parnaíba no lado piauiense. A bacia do rio Longá abrange uma área de $22.900 \mathrm{~km}^{2}$ representando cerca de $6,67 \%$ da área da bacia hidrográfica do Parnaíba (LIMA, 2006) conforme se observa no Mapa 01. 

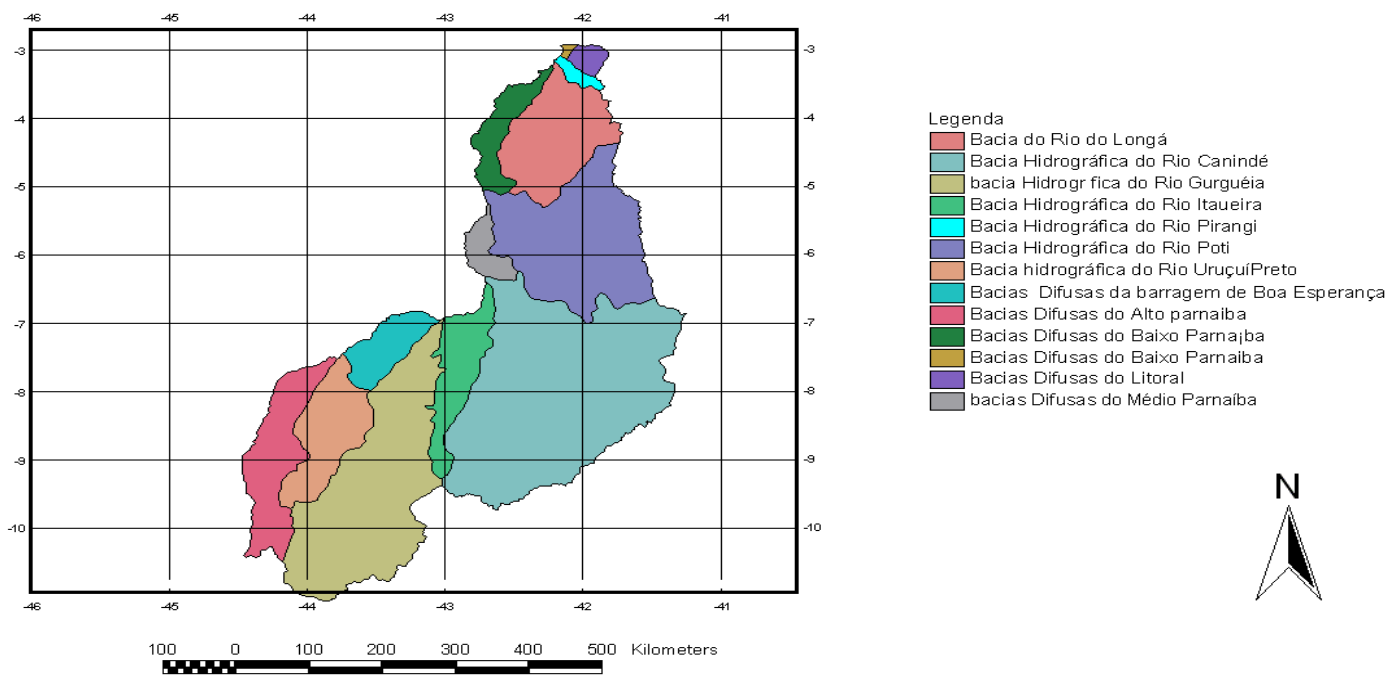

Mapa 01 - Bacias Hidrográficas do Estado do Piauí. Fonte: LIMA, apud SEMAR 2006.

A bacia do rio Longá localiza-se no baixo curso da bacia hidrográfica do rio Parnaíba e configura-se como uma importante bacia para a região norte do estado do Piauí, com uma capacidade hídrica de 5,4 bilhões de metros cúbicos (RIVAS, 1996). É importante salientar que na classificação vigente do relevo piauiense segundo Lima (1987), a bacia do rio Longá se localiza em duas feições geomorfológicas: 1- planalto oriental da bacia sedimentar do Piauí/ Maranhão e 2- baixos planaltos do médio baixo Parnaíba. De acordo com Baptista (1981), a bacia do rio Longá possui uma declividade de 0,4m e uma extensão de 320 km. O Mapa 02 apresenta a rede de drenagem dessa bacia.

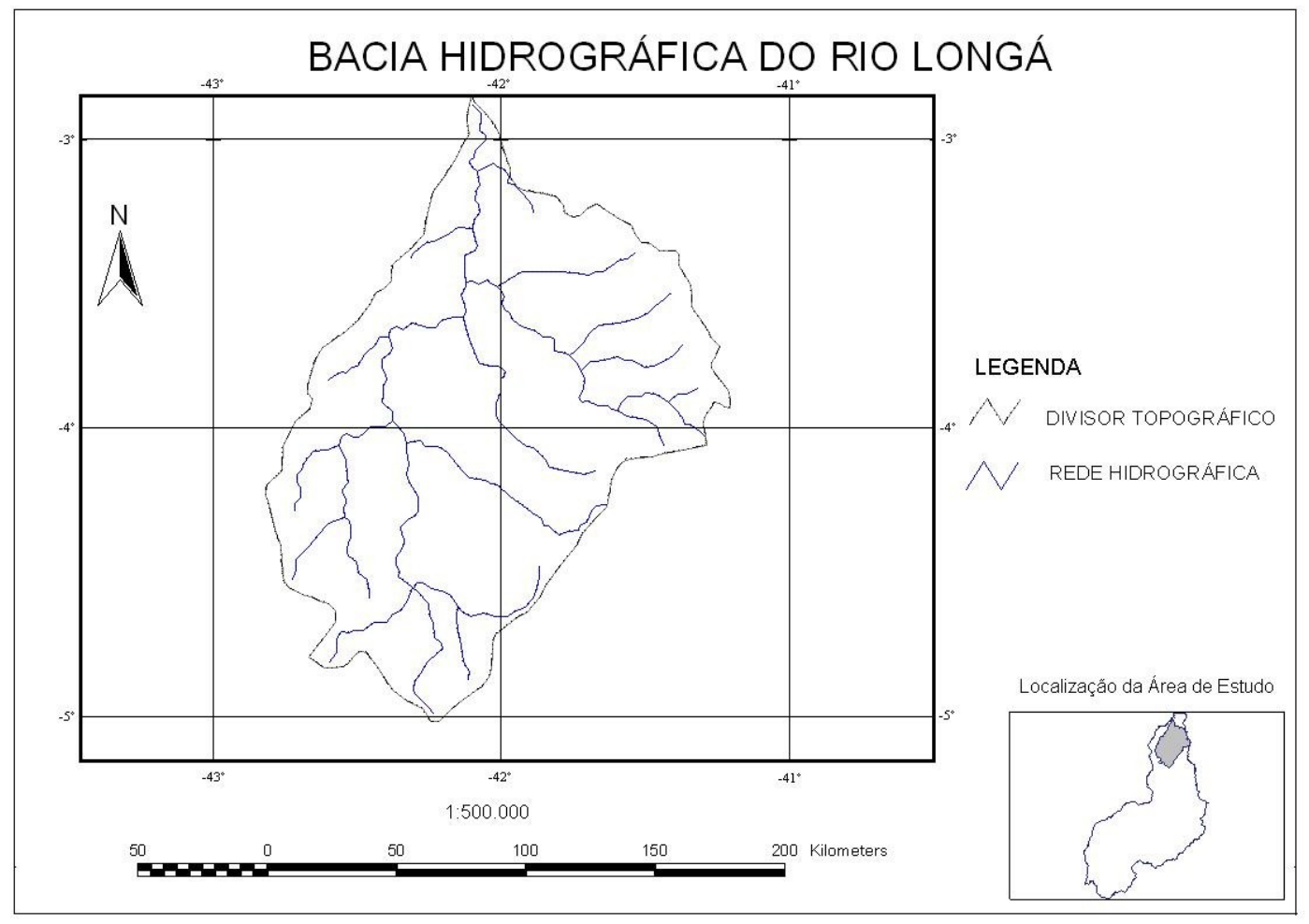


Mapa 02: Bacia hidrográfica do rio Longa. Fonte: SEMAR apud LIMA, 2006.

De acordo com o Mapa 02 é possível verificar que o rio principal é abastecido por extensa rede de drenagem. Ressalta-se que dessa rede de drenagem há alguns afluentes perenes e outros intermitentes. A jusante do município de Esperantina o rio Longá recebe dois afluentes perenizados por barragens no caso os rios dos Matos e o Piracuruca o que esses rios possibilita o aumento da vazão próximo a foz (Foto 01)

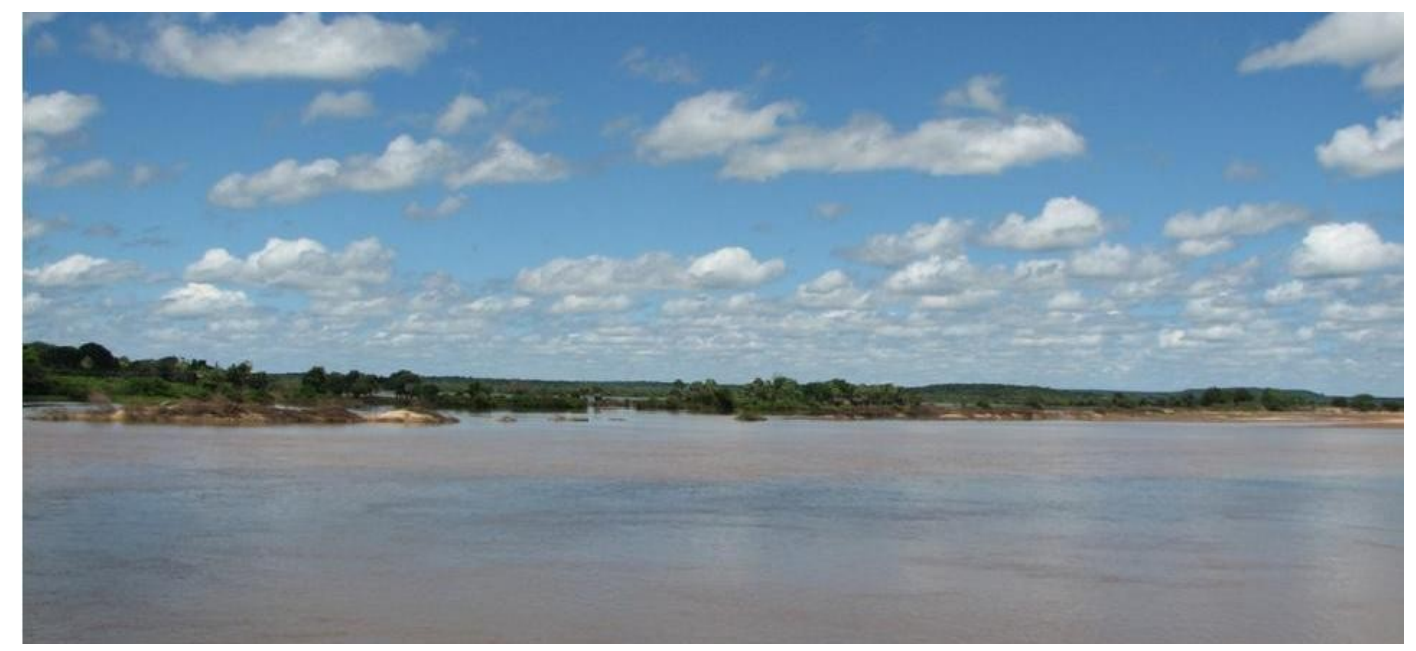

Foto 01: Foz do rio Longa. Fonte: Araújo, 2008.

É importante ressaltar que na bacia do rio Longá há um predomínio de uma vegetação de transição, com espécies de cerrado e de caatinga sendo um bom exemplo dessa realidade o município de Campo Maior onde se localiza o "Complexo de Campo 
Maior", no qual, existem as chamadas 'playas' que são terrenos alagadiços formados em razão de possuírem uma camada 'B' praticamente impermeável no seu perfil de solo.

\section{OS ANTECEDENTES HISTÓRICOS DE POVOAMENTO DA BACIA DO RIO LONGÁ}

Na região norte do estado do Piauí, a bacia hidrográfica do rio Longá teve uma grande importância para o povoamento setentrional do estado. Inicialmente esse povoamento concretizou-se com a criação de vilas com o propósito principal de realizar a atividade pecuária.

Dentre, as várias cidades localizadas na bacia do rio Longá, Campo Maior pode ser considerada uma das primeiras a se formar, pois o seu povoamento começou em meados do século XVII quando da criação da freguesia de Santo Antônio do Surubim. Já no século XVIII essa freguesia é levada a categoria de cidade na data aproximada de 19 de junho de 1761. É importante ressaltar que nessa freguesia a principal atividade era a criação de gado vacum. Dessa forma, na Foto 02 observa-se uma propriedade típica do município de Campo Maior que conseguiu resistir à ação do tempo:

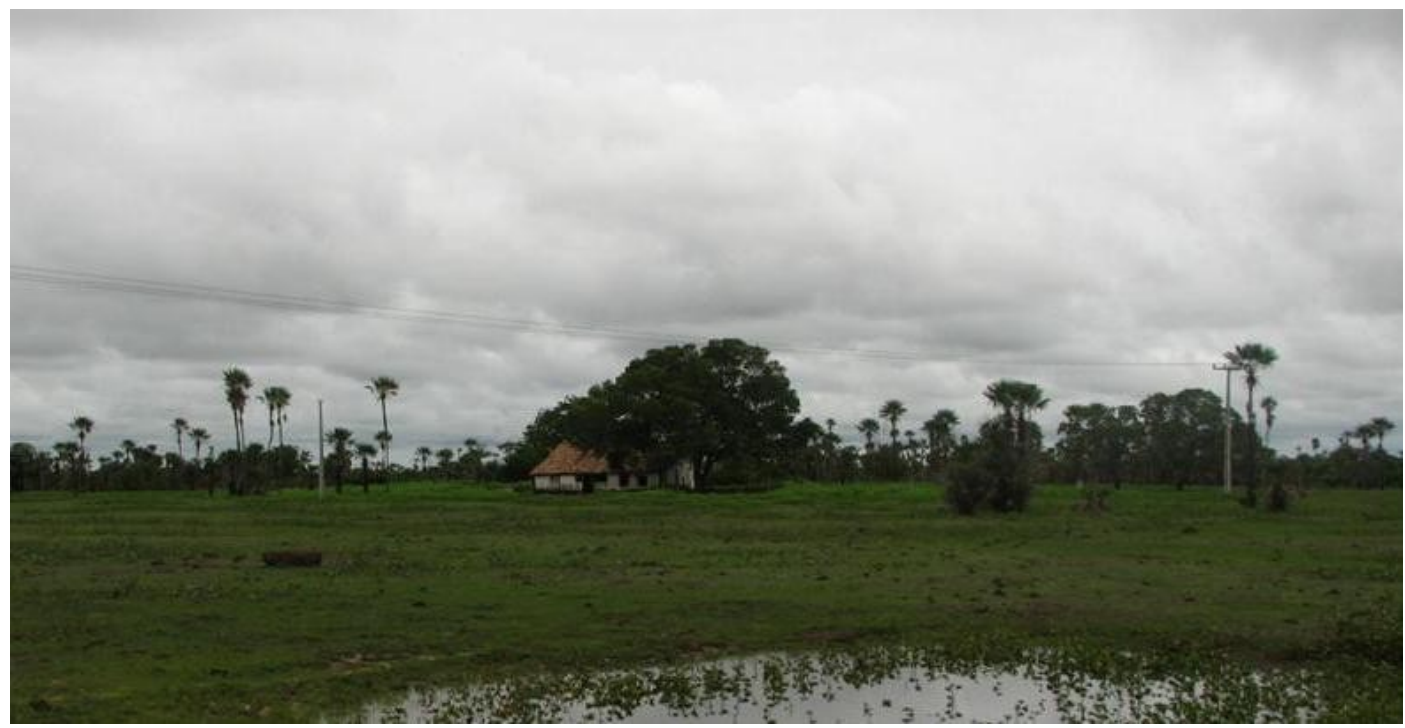

Foto 02: Típica casa sede de antiga fazenda de criação de gado na bacia do rio Longá Fonte: Araújo, 2008.

Barras inicia seu povoamento em meados do século XVIII através da implantação de uma fazenda para a criação de gado instalada na margem do rio Longá. Devido a sua localização foi instalada a freguesia no ano de 1839 sendo que depois essa freguesia foi 
transformada em Vila no ano de 1841. A vila de Barras foi transformada em cidade através do decreto estadual no 1 de 28 de dezembro de 1889 .

$\mathrm{O}$ atual município de Batalha foi importante para o povoamento da bacia do rio Longá. Desde o século XVIII essa região já era povoada sendo que ano de 1853 foi levada a categoria de freguesia sendo que em 1858 foi instalada a Vila. É importante ressaltar que esse município tem a categoria de cidade no ano de 1938.

Esperantina surgiu através da implantação de uma fazenda de gado no ano de 1706. No ano de 1920 esse local foi transformado em Vila sendo que em 15 de dezembro de 1938 Esperantina recebe a categoria de cidade.

Na foz do rio Longá no município de Buriti dos Lopes que por sua vez teve o seu povoamento em meados do século XIX sendo que no início do século XX criou-se a Vila, mas na data de 31 de dezembro 1938, Buriti dos Lopes recebe a denominação de cidade. A sede do município fica um pouco mais afastada da margem do rio, tendo em vista as condições físicas do terreno para a expansão da área com edificações. Na Foto 03 vê-se um dos primeiros núcleos de povoamento do municípios, denominado Barra do Longá, situado à margem do rio Parnaíba

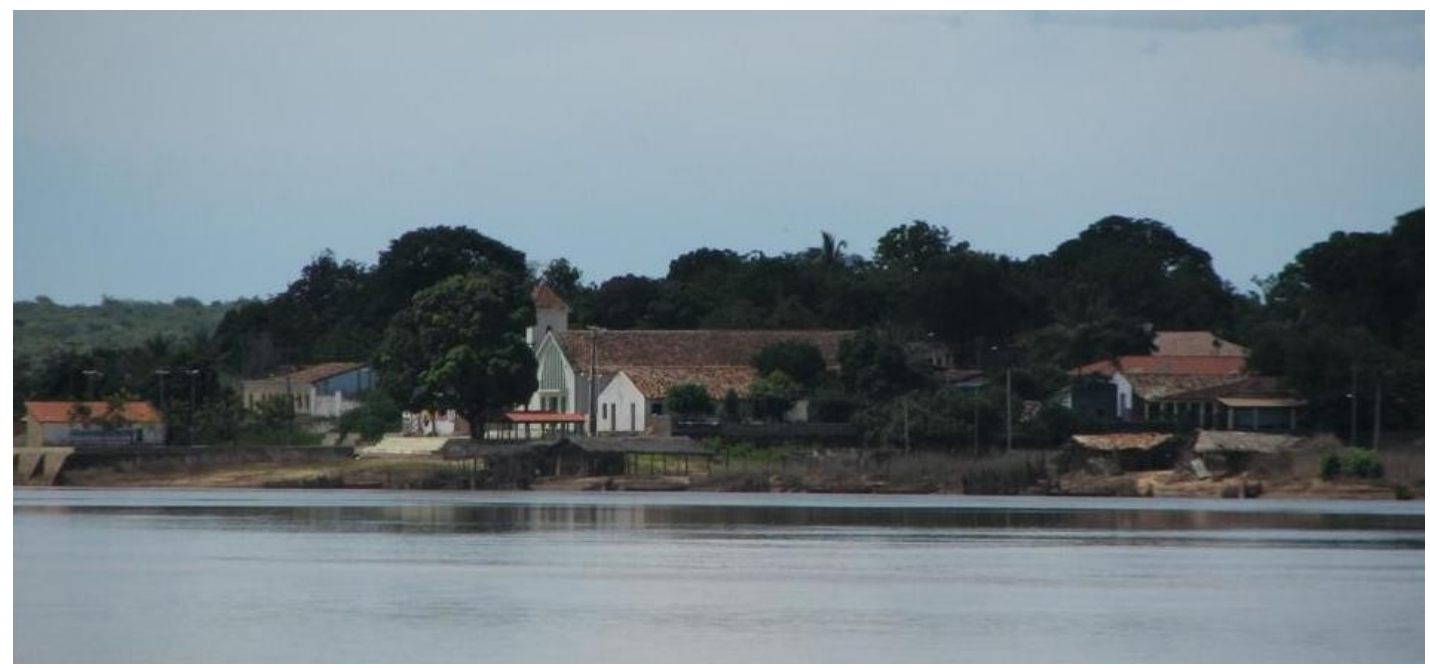

Foto 03: Povoado Barra do Longá, situado na foz do rio Longá, no município de Buriti dos Lopes, Fonte: Araújo, 2008.

É importante ressaltar que a foz desse rio se dá através de um delta ao desaguar no rio Parnaíba com vários canais, como se pode observar na Foto 01

Ainda no século XIX, a parte próxima às nascentes do rio Longá recebe o povoamento que viria a formar o município de Alto Longá sendo que no ano de 1875 criouse a vila dos Humildes que só foi levada à categoria de cidade no ano de 1939 já com o nome 
de Alto Longá em razão da sua localização próxima as nascentes do rio. Conforme visto nos parágrafos anteriores, o vale do Longá foi povoado ao longo dos séculos XVII ao XIX na medida em que iriam se desenvolvendo algumas localidades atreladas à atividade de criação de gado. Fica nítida a importância da atividade pecuária para o povoamento ao longo do vale do Rio Longá. Essa dinâmica no povoamento é destacada por Queiroz (2006, p. 21) ao afirmar que:

A pecuária piauiense enquanto extensiva era desenvolvida em grandes propriedades e não tinha muitas exigências quanto à mão de obra quer em termos quantitativos quer qualitativos. Estas características aliadas a sua importância também como economia de subsistência induziam a ocupação de extensas áreas de terras em que ela se tornava a atividade principal.

Dessa forma, a atividade pecuária representou um importante instrumento no povoamento do estado do Piauí sendo que essa atividade era de certa forma rentável para os pecuaristas piauienses em razão da exportação da carne salgada para a região mineradora da colônia no século XVIII e também para as áreas produtoras da cana de açúcar.

Em 2007, a população na bacia do Longá estava distribuída pelos os municípios que a compõem conforme a Tabela 01.

\begin{tabular}{|c|c|}
\hline Municípios & $\begin{array}{c}\text { População } \\
\text { (no de habitantes) }\end{array}$ \\
\hline Alto Longá & 13.612 \\
\hline Campo Maior & 44.548 \\
\hline Barras & 43.328 \\
\hline Esperantina & 36.190 \\
\hline Batalha & 25.724 \\
\hline Buriti dos Lopes & 19.150 \\
\hline Coivaras & 3.797 \\
\hline Nossa Senhora de Nazaré & 4.0848 \\
\hline Boqueirão do Piauí & 6.325 \\
\hline Cabeceiras do Piauí & 9.438 \\
\hline Boa hora & 6.086 \\
\hline São José do Divino & 5.045 \\
\hline Caraúbas & 5.371 \\
\hline Caxingó & 5.023 \\
\hline Murici do Portelas & 7.655 \\
\hline
\end{tabular}


Diante dos dados apresentados pode-se verificar que o vale do rio possui uma maior quantidade populacional no seu médio curso em especial nos municípios de Barras, Esperantina e Batalha. Essa discussão é importante, pois os recursos desse rio são utilizados pelos moradores das zonas urbanas e rurais nesses municípios sendo que na zona rural as águas do rio são utilizadas para a irrigação de lavouras permanentes, por exemplo, no município de Barras que produz uma grande quantidade de melancia e também Buriti dos Lopes que tem uma grande produção de arroz realizada nas áreas de inundação da foz do rio Longá.

\section{ATIVIDADES ECONÔMICAS NA BACIA HIDROGRÁFICA DO RIO LONGA}

Ao analisar uma determinada bacia hidrográfica é de suma importância um entendimento dos tipos de atividades econômicas presentes nesse espaço. Dessa forma em um primeiro momento será analisado a atividade extrativista da carnaúba, principal produtos do extrativismo vegetal que continua em alta no mercado internacional e no segundo momento serão vistas as várias atividades de subsistência realizadas pelos moradores locais.

A extração dos produtos da carnaúba desde o final do século XIX e início do século XX ocorre de uma maneira constante em razão da sua importância econômica para os diversos sujeitos envolvidos nesse processo. Na primeira metade do século XIX, "a elevação dos preços da cera de carnaúba no mercado internacional (final da década de 1930 até meados da década de 1940), intensificou as atividades que envolviam a sua produção com consequente forte circulação monetária naquele estado" (ARAÚJO, 2008, p. 198). É preciso ressaltar que esse período áureo não conseguiu manter uma estabilidade para todos os envolvidos nesse processo, pois o mercado da cera era muito dependente do mercado externo continuando ainda cíclico e instável (SOUZA, et al., 2006).

É importante destacar que em todos os municípios presentes na bacia do rio Longá há extração da palha de carnaúba (Tabela 02).

Tabela 02: Produção de pó de carnaúba nos municípios da bacia do rio Longá - 2007 Produção 


\begin{tabular}{lc|}
\hline & Pó (t) \\
\hline Campo Maior & 1.275 \\
Barras & 188 \\
Esperantina & 160 \\
Batalha & 395 \\
Buriti dos Lopes & 325 \\
Coivaras & 109 \\
Nossa Senhora de Nazaré & 133 \\
Boqueirão do Piauí & 126 \\
Cabeceiras do Piauí & 101 \\
Boa hora & 03 \\
São José do Divino & 160 \\
Caraúbas & 123 \\
Caxingó & 213 \\
Murici do Portelas & 170 \\
Alto Longá & 57 \\
\hline
\end{tabular}

Fonte: IBGE, 2007

Ressalte-se que as palhas de carnaúba são utilizadas como adubos e na produção artesanal de produtos utilitários e de decoração. Na Foto 04 mostra-se palhas expostas ao sol para a secagem.

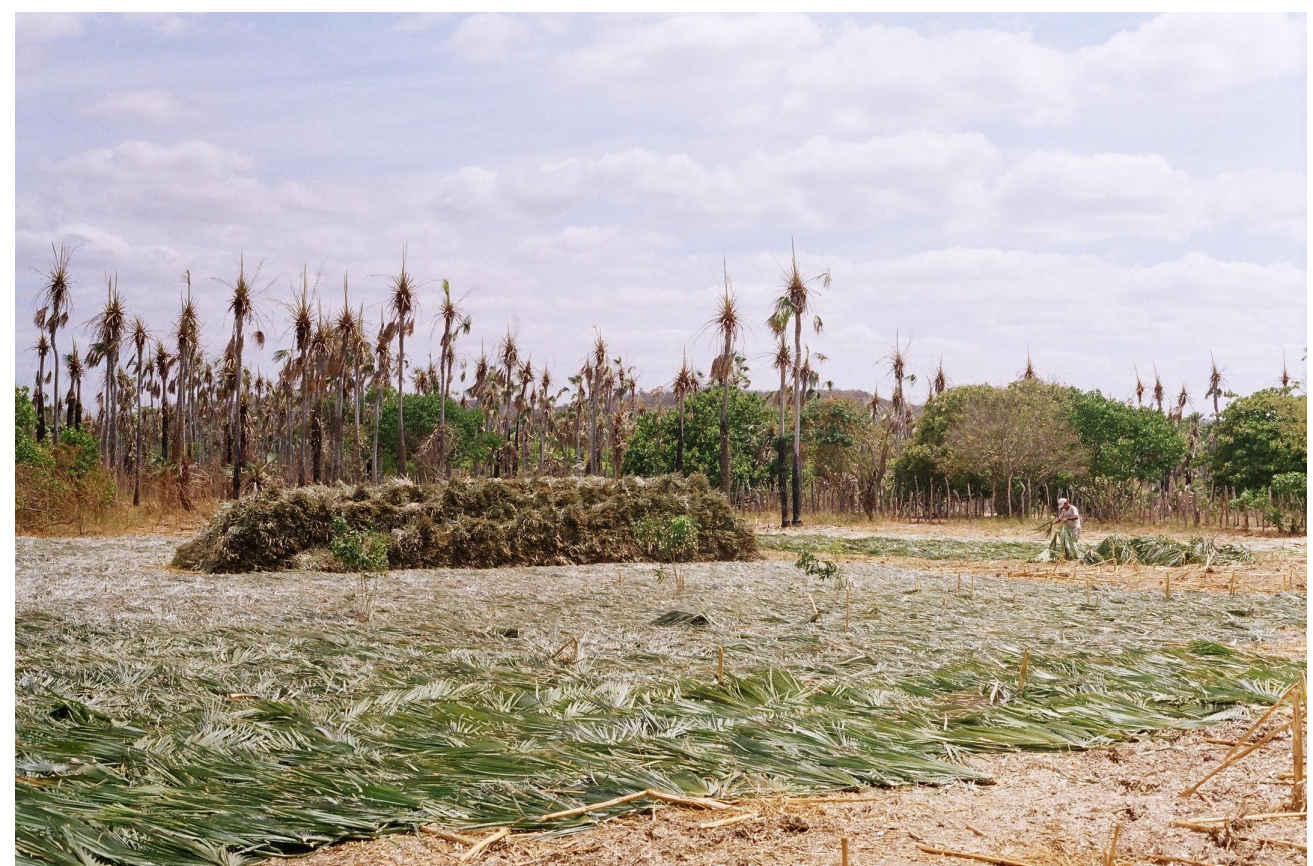

Foto 04: Ao fundo palmeiras de carnaúba após corte das palhas; no primeiro plano palhas de carnaúba secando ao sol e outras já recolhidas após secagem. Fonte: Araújo (2006)

Ao longo da bacia do rio Longá existam também outras atividades econômicas relacionadas ao extrativismo vegetal como a extração de madeira e o babaçu. Dessa forma, a atividade de extração de madeiras deve ser observada, pois essa atividade deixa grandes impactos ambientais para as formações vegetais presentes ao longo da bacia do rio, 
observando-se mesmo até a retirada de matas ciliares para cultivos, produção de carvão e madeira. 
Tabela 03: Extração de madeira e babaçu nos municípios da bacia do Rio Longá- 2007

\begin{tabular}{|c|c|c|c|c|}
\hline \multirow[b]{2}{*}{ Município } & \multicolumn{4}{|c|}{ TIPOS DE USOS DA VEGETAÇÃO } \\
\hline & $\begin{array}{c}\text { Madeira-carvão } \\
\text { vegetal (ton.) }\end{array}$ & Madeira- lenha $\left(\mathrm{m}^{3}\right)$ & $\begin{array}{c}\text { Madeira em tora } \\
\left(\mathrm{m}^{3}\right)\end{array}$ & Babaçu (ton.) \\
\hline Campo Maior & 465 & 7.240 & & \\
\hline Barras & 1.788 & 8.262 & 352 & 782 \\
\hline Esperantina & 59 & 4.350 & 150 & 330 \\
\hline Batalha & 100 & 21.131 & 1.299 & 141 \\
\hline Buriti dos Lopes & 58 & & & \\
\hline Coivaras & 36 & 3.256 & & 3 \\
\hline Nossa Senhora de & & & & \\
\hline Nazaré & 47 & 1.193 & & \\
\hline Boqueirão do Piauí & 81 & & & 2 \\
\hline Cabeceiras do Piauí & 71 & 1.430 & 380 & 76 \\
\hline Boa hora & 88 & 8.250 & & \\
\hline São José do Divino & 3 & 5.079 & & \\
\hline Caraúbas & 35 & 841 & & \\
\hline Caxingó & 29 & 714 & & \\
\hline Murici do Portelas & 51 & 1.107 & & \\
\hline Alto Longá & 780 & 21.020 & 2.011 & \\
\hline
\end{tabular}

Fonte: IBGE, 2007

Diante dos dados apresentados na Tabela 03, os municípios localizados ao longo da bacia do rio Longá utilizam-se de várias maneiras os recursos vegetais. Com relação aos usos da madeira é importante ressaltar que há uma preponderância para a lenha o que de certa forma acaba por trazer grandes prejuízos para o meio ambiente através da queima da madeira em fornos de indústrias (padarias, cerâmicas, extração de óleos, sabão entre outras) e também para o consumo doméstico. Outro aspecto preocupante dentre essas atividades é a extração de madeira para a obtenção da matéria-prima para a construção de casas, cercas, currais, e outros usos. Em Alto Longá, por exemplo, há uma quantidade de

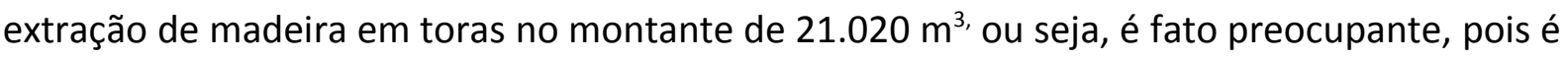
nesse município que se localizam as nascentes do rio Longá o que pode colocar em risco a existência do rio.

As nascentes do referido rio localizam-se na localidade Lagoa do Longá no município de Alto Longá. Essa área não se encontra em boas condições naturais devido a alguns fatores, principalmente os antrópicos. Conforme Costa Neto (2002, p.20) "Constatamos, entretanto que hoje, a nascente em estudo apresenta degradação decorrente de diversos fatores apontados pelos entrevistados como sendo desmatamento, perfuração de poços, ausência de chuvas". 
É importante ressaltar que aliada à extração vegetal (carnaúba, madeira, babaçu) também existe a criação de bovinos, suínos, caprinos e ovinos. Na Foto 05 mostra-se animais pastando em campos de pastagem natural, típicos da área no período chuvoso.

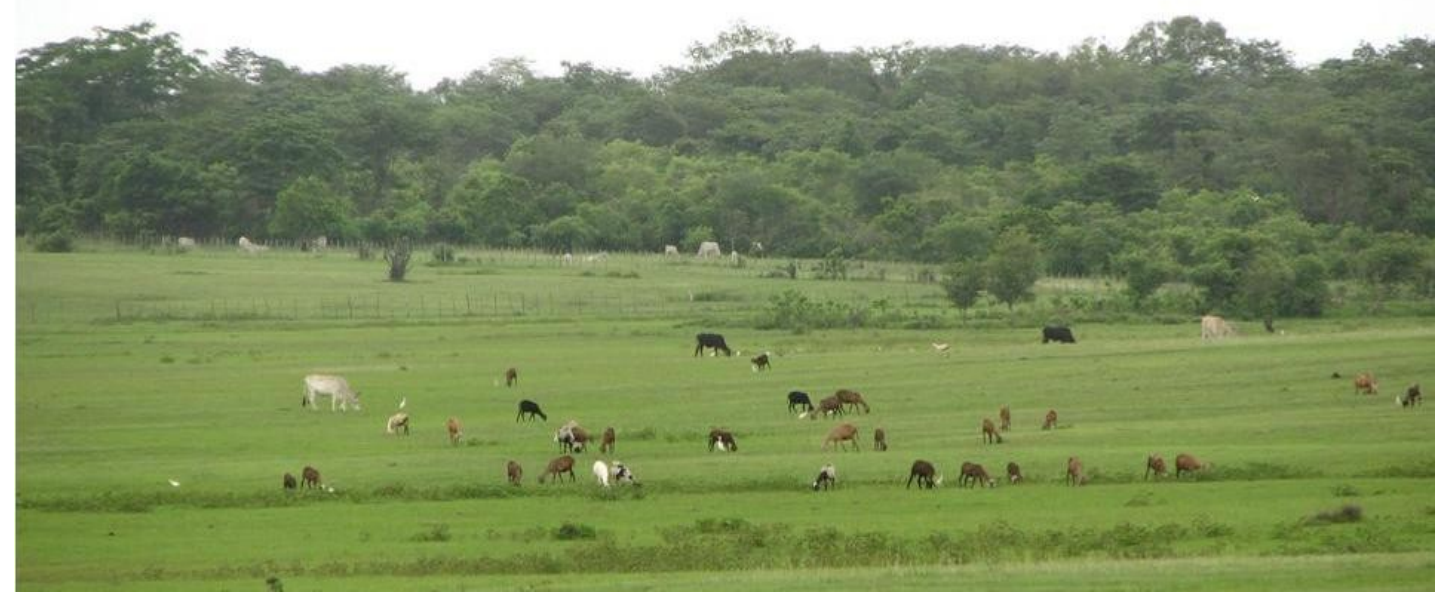

Foto 05 Criação extensiva de gado na bacia do rio Longa. Fonte: Araújo (2008)

Na Foto 05 é possível verificar uma grande variedade de animais que são criados na sua grande maioria por pequenos e médios proprietários que utilizam esses animais como uma forma de subsistência e para a comercialização da carne e do couro. Ao analisar a Foto 05 é possível afirmar que esse tipo de criação acaba por trazer algumas conseqüências para o meio natural em razão do intenso pisoteamento o que pode trazer em uma compactação do solo. Essa forma de criação já era feita há muitos séculos atrás, conforme visto nas páginas anteriores. Para Rivas (1996), a pecuária no seu conjunto é em alguns casos realizada com técnicas rudimentares pela falta de assistência do governo juntamente pela inexistência de um manejo apropriado para as pastagens. Na Tabela 04 tem-se a distribuição desses rebanhos pelos os municípios: 
Tabela 04: Rebanho de bovinos, caprinos, suínos e ovinos nos municípios da bacia do rio Longá - 2007

\begin{tabular}{l|rrrrr|}
\hline \multirow{2}{*}{ Municípios } & \multicolumn{4}{|c|}{ Rebanhos } \\
\cline { 2 - 5 } & Bovino (cabeças) & Suíno (cabeças) & Caprino (cabeças) & Ovino (cabeças) \\
\hline Campo Maior & 30.629 & 25.528 & 33.458 & 29.480 \\
Barras & 18.642 & 33.841 & 22.428 & 7.979 \\
Esperantina & 14.528 & 15.888 & 18.713 & 6.521 \\
Batalha & 22.731 & 23.340 & 33.297 & 18.760 \\
Buriti dos Lopes & 15.275 & 4.045 & 2.338 & 2.015 \\
Coivaras & 3.946 & 3.439 & 4.838 & 5.024 \\
Nossa Senhora de & & & & \\
Nazaré & 5.024 & 8.061 & 4.853 & 11.233 \\
Boqueirão do Piauí & 3.671 & 4.381 & 3.699 & 3.535 \\
Cabeceiras do Piauí & 7.917 & 7.126 & 13.410 & 13.410 \\
Boa hora & 2.045 & 5.189 & 2.192 & 2.192 \\
São José do Divino & 8.226 & 3.344 & 7.065 & 6.548 \\
Caraúbas & 9.442 & 4.212 & 2.720 & 2.623 \\
Caxingó & 5.985 & 2.412 & 2.372 & 1.991 \\
Murici do Portelas & 5.909 & 8.146 & 5.703 & 1.434 \\
Alto Longá & 11.737 & 17.005 & 22.526 & 25.194 \\
\hline
\end{tabular}

Fonte: IBGE, 2007

Diante dos dados apresentados é possível afirmar que os municípios que compõem a bacia do rio Longá possuem uma variedade importante na criação de animais para oferta de carne e de matéria-prima para a indústria do couro. O município de Batalha apresenta um grande rebanho de caprinos e anualmente promove o Festival do Bode que já virou uma tradição nesse município. No município de Campo Maior ainda há um predomínio na criação de bovinos talvez seja em razão do seu passado que detinha uma grande de quantidade de cabeças de bois para o mercado interno na época do Brasil Colônia.

Assim, a atividade pecuária ainda tem uma forte função social, pois esses rebanhos tais como: suínos, ovinos e caprinos têm um caráter de subsistência para as pessoas de baixa renda principalmente nas zonas rurais desses municípios. Aliada a pecuária os projetos de irrigação configuram-se como um importante instrumento econômico em alguns municípios ao longo do seu curso como é o caso de Barras no cultivo de melancia e Alto Longá e Buriti dos Lopes no cultivo do arroz.

\section{ATIVIDADES TURÍSTICAS NO RIO LONGA}

Ao abordar sobre o uso do rio Longá na atividade turística é de grande importância ressaltar o Parque Ecológico Cachoeira do Urubu. Esse parque localiza-se entre os municípios de Esperantina e Batalha. Essa Unidade de Conservação possui uma área de 7,54ha. No período chuvoso devido ao aumento das águas do rio é formada uma bela 
paisagem através de um desnível no leito rochoso do rio na área do parque e que segundo Batista (1981) essa queda d'água possui uma altura de $13,40 \mathrm{~m}$ formando um belo espetáculo natural, o qual pode ser verificado na Foto 06.

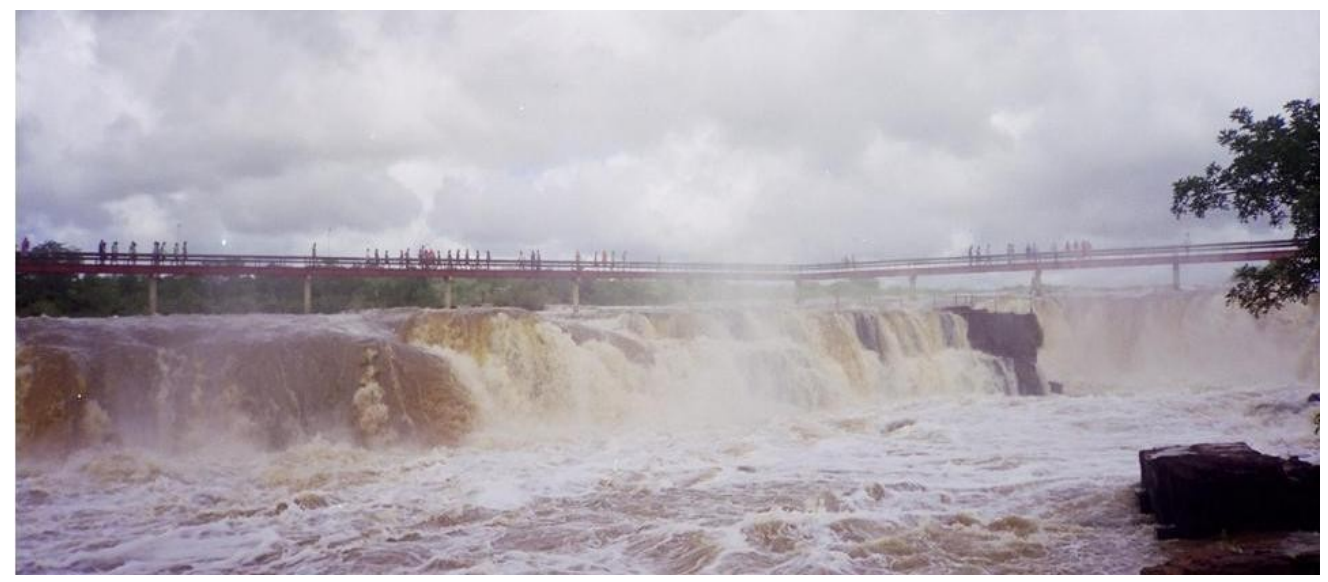

Foto 06: Cachoeira do Urubu no rio Longá (Esperantina/Batalha-PI. Fonte: Araújo (2008)

A cachoeira do Urubu é considerada um dos grandes atrativos turísticos do estado do Piauí, pois a cada ano reúne uma grande quantidade de turistas. Na década de 1990 já se faziam estudos sobre o seu uso como atrativo turístico. Feitosa (1995, p. 45) enfatizava que os "turistas ao visitarem o local causam degradação, como pisoteamento da vegetação rasteira e de outras espécies, pássaros são sacrificados, das rochas são retiradas amostras sem fins que justifiquem tais atitudes".

Existem outras conseqüências relacionadas ao turismo praticado na cachoeira do urubu como, por exemplo: lixo de vários materiais como: vidro, papel e restos de comida, sendo que é muito comum no período de alta estação alguns turistas acenderem fogueiras para o preparo do peixe. O certo é que a degradação não ocorre exclusivamente em razão do turismo, mas também pelo fato da existência de outras atividades antrópicas. Assim, fica evidente uma realidade preocupante no Parque Ecológico Cachoeira do Urubu, pois são verificadas ações antrópicas como desmatamento, caça, pesca predatória, fogueiras e entre outras formas que comprometem principalmente a biota presente nesse espaço. Faz-se necessário, então adotar medidas para reverter essa situação através da educação ambiental e ainda um melhor planejamento para o turismo nessa área.

\section{CONCLUSÃO}

Diante dos fatos apresentados, a bacia do rio Longá possui vários afluentes de caráter intermitentes e perenes. Essa bacia teve o seu povoamento através da atividade 
pecuária ainda no século XVII sendo que nos dias atuais há outras atividades nessa região que possibilitam uma maior dinâmica da economia local. É preciso ressaltar que o poder público deve realizar estudos para descobrir os potenciais dessa bacia aliado a implantação do comitê de bacia desse rio para um uso eficaz das águas para o uso industrial bem como pelas comunidades tradicionais sendo que deve existir uma maior fiscalização dos órgãos competentes para a questão da extração de madeira nessa região, pois ao longo desse estudo percebeu-se que uma grande quantidade de madeira é extraída nos municípios onde se localizam as nascentes do rio Longá.

\section{THE LONGÁ RIVER AND THE SETTLEMENT ON NORTH OF PIAUÍ}

ABSTRACT: The Longá's River basin represented important factor of settlement of Noth of Piau, in face of the environment resources it presents by itself. Both in relation to the availability of groundwater and surface water, such as biodiversity characterized by rich flora and fauna which highlight species that facilitated the installation of the first inhabitants, also for providing fruits for human consumptin, as well as wood and straw to build houses and construction of utility goods, such as the tucum, babaçu and carnaúba. It should be noted that the canauba wax still remains as one of the main exports of Piauí in this first decade of this century. Besides the traditional economic activities in the Longa's river basin since the beginning of colonization, it was possible to observe the use of modern production techniques, such as the use of irrigation, which reinforces the importance of water resources present there, especially the main river, which is the the Longa River. Thus, this study was developed with the aim to characterize the natural aspects, to understand the settlement process, to identify teh most expressive economical activities developed in this basin área and also to characterize the most predominant turistic activity. The methodology was based on examinations of bibliographic material on the subject, such as books, articles, monographs, Internet research and on-site observation. It can be concluded that the basin requires attention of public officials and communities that inhabit them, as preventive actions must be taken to conserve this rich heritage of Piaui.

KEY WORDS: Process of Settlement, Cattle-raising, Plant Extraction, Tourism. 


\section{REFERÊNCIAS}

ARAÚJO, José Luís Lopes. O rastro da carnaúba no Piauí. Revista mosaico. V. 1, n.2, p. 198205, jul/dez. 2008.

BAPTISTA, João Gabriel. Geografia física do Piauí. 2. ed. Teresina: Comepi, 1981, 361p.

COSTA NETO, Cassimiro. Fatores de degradação da nascente do rio Longa. In: $A$ degradação das nascentes do rio Longá- Alto Longá -PI. Teresina: [s.n], 2002, p. 20- 22. FEITOSA, Maria Suzete Sousa. Caracterização geoambiental da região da Cachoeira do Urubu - PI. Carta Cepro, Teresina. V. 16, p. 32-46, 1995.

IBGE (Instituto brasileiro de geografia e estatística) censo 2007- cidades@. Disponível em: www. Ibge. gov.br. Acesso em: 30 maio. 2009, 11:30

LIMA, Iracilde Maria de Moura Fé. Elementos naturais da paisagem. In: ARAÚJO, José Luís Lopes. (Coord.). Atlas escolar do Piauí: geo-histórico e cultural. João Pessoa: Grafset, 2006. p 39- 77.

QUEIROZ, Teresinha. A pecuária. In: Economia piauiense: da pecuária ao extrativismo. 3. ed. Teresina: edufpi, 2006. p. 19- 25.

RIVAS, Margarete Prates (Coord.). Macrozoneamento geoambiental da bacia do rio Parnaíba. Rio de Janeiro: IBGE. 1996, 111p.

SOUZA, Gildênio Assenço de et al. Os canais de comercialização internacionais da cera de carnaúba do estado do Piauí. In: GOMES, Jaíra Maria de Alcobaça; SANTOS, Karla Brito dos; SILVA, Marcos Soares (Orgs.). Cadeia produtiva da cera de carnaúba: diagnósticos e cenários. Teresina: Edufpi, 2006, p. 61- 85. 